www.jmscr.igmpublication.org

Index Copernicus Value: 79.54

ISSN (e)-2347-176x ISSN (p) 2455-0450

crossrefDOI: https://dx.doi.org/10.18535/jmscr/v7i3.115

\title{
Comparison of Placental Parameters with Foetal growth in North Indian Population
}

\author{
Authors \\ Dr Ratesh Kumar Munjal ${ }^{1}$, Dr Kunal Chawla ${ }^{2^{*}}$ \\ ${ }^{1}$ Associate Professor, Department of Anatomy, ESIC Medical College \& Hospital, Faridabad, Haryana \\ Phone: 8894286153, Email: rateshmunjal@gmail.com \\ ${ }^{2}$ Assistant Professor, Department of Anatomy, IGMC, Shimla, Himachal Pradesh \\ *Corresponding Author \\ Dr Kunal Chawla
}

Email: drkunalchawla@gmail.com, Phone: 9914113291

\begin{abstract}
A healthy placenta is a single most important factor for foetal wellbeing. Main mass of placenta is formed by villi. The purpose of this study is to correlate placental parameters to foetal weight. Thirty placenta were collected from two Govt. Medical College, Chandigarh and ESIC Medical college, Faridabad and divided into two groups i.e. placentae with foetal weight less than $2.5 \mathrm{~kg}$ and foetal weight $2.5-3.5 \mathrm{~kg}$. After morphological, Histological examination was done with $H \&$ E, Van Gieson and Masson trichrome staining. Villous volume was calculated by using point counting technique as described by Mathur et al. Volume of villi was considerably less $(p<0.01)$ in placenta of low birth weight.

Keywords: Placenta, Chorionic Villi, Histomorphomtery, Foetal weight.
\end{abstract}

\section{Introduction}

The functional unit of placenta is villi. It has average size of 30-40 $\mu \mathrm{m}$. Maternal blood bathes the villi from intervillous space and carry out various functions, like respiration, excretion and nutrition. Volume of villi continuously increases with advancement of pregnancy ${ }^{1}$. Adverse pregnancy outcome is associated with placental growth restriction or hypertrophy ${ }^{2}$.Villous volume is mainly responsible for foetal growth ${ }^{3}$, the aim of the current study is to compare various placental parameters and birth weight with help of histomorphometric study.

\section{Material \& Method}

The present study was done in two Govt. Medical colleges. Study material was placentae obtained either by normal vaginal delivery or caesarean section. Mothers of the age group 20-35 years, gestational age $32-40$ weeks were included. Total of thirty placenta were collected. Fifteen placentae were from mother of low foetal weight $(<2.5 \mathrm{~kg})$ and 15 placentae were from mother of normal foetal weight $(2.5-3.5 \mathrm{~kg})$. Exclusion criteria was mother with history of Diabetes Mellitus, Hypertension and any disease associated with development of placenta and foetus.

Morphological examination of each placenta was done and characters like weight, volume, size, 
shape, diameter, site of attachment of umbilical cord, cotyledon structure etc were noted. Volume of placenta was obtained by fluid displacement method and surface area was measured by formula, Surface area $=\mathrm{p}$ x L x B [L is Radius of placenta along the length, $B$ is Radius of placenta along the breadth].

Birth weight was taken using electronic weighing machine with accuracy of \pm 10 gram.Mean value along with standard deviation were calculated for each parameter. Four specimens were taken from each fresh placenta after removal of deciduae and fixed in $10 \%$ formalin solution. Histological staining was done with Haemotoxylin \& Eosin (Harris's alum haematoxylin), Van Gieson and Masson's trichrome method. Slides were studied under light microscope. Size of villous diameter was measured with the help of micrometer eye piece.

Relative component of villous and inter villous space were calculated by modified point counting technique as described by Mathur ${ }^{4}$ et al. When a composite organ is examined with a grid, the relative volumes of the components are equivalent numerically to their relative areas on cut surface. A grid was prepared by drawing 25 points at equal distance on a white sheet. Image of slide was projected on the white sheet marked with grid. This was made possible by attaching a mirror to the monocular eye piece of microscope. Points on grid were used as counting unit. If a point lay on a measured component, it was counted as a hit for that component. Twenty different fields were examined in each section, and in all, a minimum of 500 points were counted in each slide. The proportion of grid points falling on the image of the placenta components indicates the proportion volume of that component. Proportion of villous and inter villous space was determined. The result was computed and analysed statistically.

\section{Result}

In low foetal birth weight placenta mean length of umbilical cord was $47.72 \pm 10.02 \mathrm{~cm}$ with range of $32-51 \mathrm{~cm}$. Mean diameter was $2.79 \pm 0.6 \mathrm{~cm}$ with range of 1.4 to $3.1 \mathrm{~cm}$. Out of 15 placentae, 13 have eccentric attachment of umbilical cord and two have central attachment. In normal foetal weight placenta, mean length of umbilical cord was $53.20 \pm 12.04 \mathrm{~cm}$ with range of $43-62 \mathrm{~cm}$. Mean diameter of umbilical cord was $3.8 \pm 1.0 \mathrm{~cm}$ with range of 3.0 to $5.1 \mathrm{~cm}$. Twelve placenta have eccentric attachment of umbilical cord and three have central attachment.

Mean placental/foetal weight ratio was $0.32 \pm 0.2$ in low foetal birth weight placenta and $0.21 \pm 0.4$ in normal foetal birth weight placentae. Surface area of low foetal weight placentae was $159.0 \pm$ $12.5 \mathrm{~cm}^{2}$ with range $140-170 \mathrm{~cm}$ and in normal placenta it was $185.6 \pm 18.3 \mathrm{~cm}^{2}$ with range of 155 $-190 \mathrm{~cm}^{2}$.

In low birth weight placenta percentage of villous volume was $45.38 \pm 5.3 \%$ and in normal birth weight placenta it was $54.59 \pm 3.7 \%$. Villous volume in low birth weight was $110 \pm 34(65-170$ $\mathrm{cm}^{3}$ ) whereas in normal birth weight was $138 \pm$ $31.02 \mathrm{~cm}^{3}$ (range $100-230 \mathrm{~cm}^{3}$ ). Mean value was significantly low $(\mathrm{p}<0.05)$.

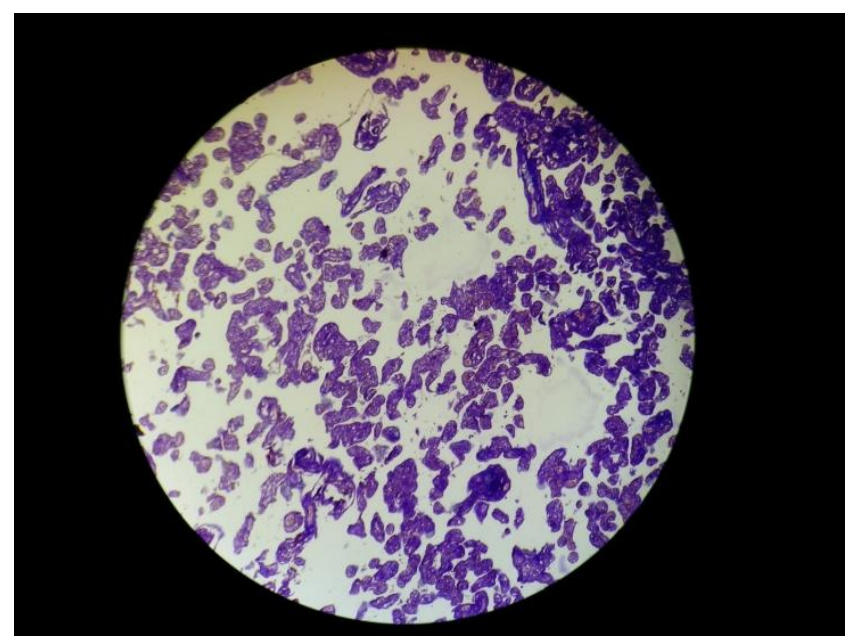

Pic 1. Photomicrograph showing bluish colour is Placental staining with Masson Trichrome of low birth weight baby placenta. Foetal weight $1.9 \mathrm{~kg}$ at 32 wk gestation 


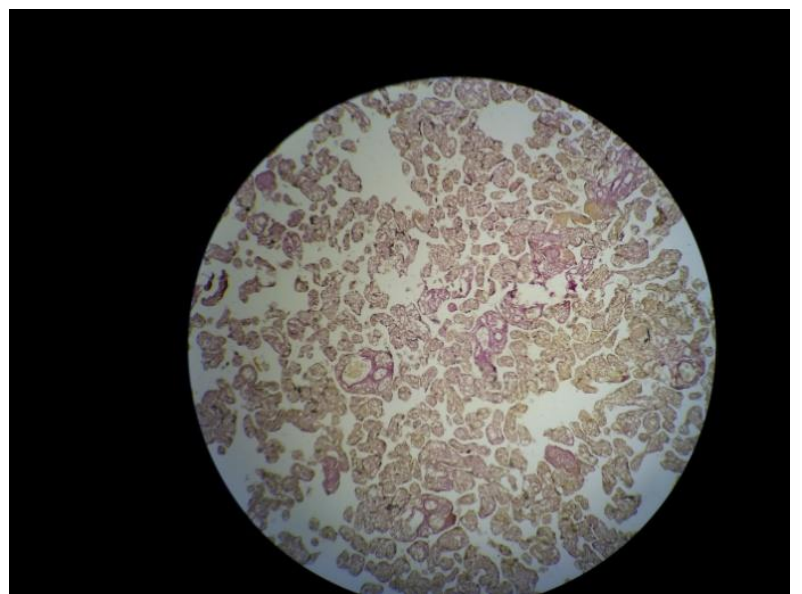

Pic 2. Photomicrograph showing red color is Van gieson staining of Foetal weight $2.9 \mathrm{~kg}$ at $38 \mathrm{wk}$ gestation

\section{Discussion}

The mean length of the cord is $50 \mathrm{~cm}$ in normal placenta according to Standring ${ }^{1}$. According to Shunji Suzuki ${ }^{5}$ et al, the normal length of the umbilical cord is $45-68 \mathrm{~cm}$. So in our study cord length correlated significantly with the weight of the baby at birth $(\mathrm{p}<0.01)$, in accordance with previous studies ${ }^{6,7}$. The mean placental/foetal weight ratios in were 0.21 in normal birth placenta which is in accordance tostudies ${ }^{8,9,10}$ of Kalra et al (0.20), but more than that described by Beck (0.14) and Rath (0.16). There was significant difference with in low birth placenta (0.32). Mean surface area of placenta in normal weight placenta was $187 \mathrm{~cm}$. The present finding is less than that described by Rath $\left(254.63 \mathrm{~cm}^{2}\right)$. There was not significant difference with in low birth placenta (159). Heidary ${ }^{11}$ et al. reported percentage volumes of the villi $(66 \%)$ and inter villous space $(34 \%)$ in cases of placenta previa of Iranian women whereas Abdalla ${ }^{12}$ et al (2016) found out values for the normally implanted placenta in Sudanese women as $65 \%$. Thus, it indicates that the site of implantation within the endometrium has no impact on the volume densities of the placental villi and the inter villous space. However, the absolute volumes of these components may be affected because the site of implantation is likely to affect the total volume of the placenta ${ }^{11}$. Villous volume differs significantly in low birth weight and normal placenta $(\mathrm{p}<$
0.01). It is in contrast to study of Aherne etal ${ }^{13}$ who concluded that villous volume of IUGR and normal pregnancy does not differ.

\section{Conclusions}

Placental structure gives valuable information for foetal growth. Volume of villi correlate significantly for foetal growth. It is the volume of villi which is mainly responsible for foetal growth. So all factors which affect villous growth like DM, HT etc should be controlled. means for comparing the parameters with and clinically determined values. The percentage volumes occupied by the placental villi in North Indian population were within the range of values reported in the previous studies for the placenta of other ethnic groups.

\section{Grants: Nil}

\section{References}

1. Thomas I. Implantation, placentation, pregnancy and parturition In: Standring $S$, Ellis H, Healy JC, Johnson D, William A, Collins P et al, editors. 39th ed. Gray's anatomy. Edinburgh: Elesevier Churchill Livingstone; 2005.p.1339-1352.

2. Novak RF. A brief review of the anatomy, histology, and ultrastructure of the fullterm placenta. Arch Pathol Lab Med 1991;115:654-59.

3. Young B, Heath JW. Wheater's functional histology. 4th ed. London: Churchill Livingstone; 2001.p.359-62.

4. Mathur S, Dasgupta P. A simple morphometric method for the study of placentae. Indian $\mathbf{J}$ Pathol Bacteriol 1974;17(4):205-210.

5. Shunji S, Yukiko F. Length of the Umbilical Cord and Perinatal Outcomes in Japanese Singleton Pregnancies Delivered at Greater Than or Equal to 34 Weeks' Gestation. J Clin Gynecol Obstet. 2012;1(4-5):5762. 
6. Wu JF, Chang SY, Hsu TY, Kung FT, Chan TC, Hsieh CH. Multivariate analyses of the relationship between umbilical cord length and obstetric outcome. Changgeng Yi Xue Za Zhi 1996; 19(3):247-252.

7. Adinma JI. The umbilical cord: a study of 1,000 consecutive deliveries. Int J Fertil Menopausal Stud 1993;38(3):175-9.

8. Kalra K, Kalra A, Gupta RK, Bhatia R, Singh K, Prasad R et al Placental morphology and histopathology in low birth weight. Indian Pediatr 1986;23:6115.

9. Beck T. Placental morphometry using a computer assisted measuring programme: reference values for normal pregnancies at term. Arch GynaecolObstet 1991;249:13547.

10. Rath G, Garg K, Sood M. Insertion of umbilical cord on the placenta in hypertensive mother. $\mathrm{J}$ Anat Soc India 2000;49(2):149-52.

11. Heidary Z. Stereological analysis of human placenta in cases of placenta previa in comparison with normally implanted controls. J. Rep. Infert. 2015;16:90-5.

12. Abdalla AM, Tingari MD, Abdalla MA. Histomorphometric parameters of normal full term placenta of Sudanese women. Heliyon. 2016;2(7):e00135.

13. Aherne W, Dunnill MS. Quantitative aspects of placental structure. J PatholBacteriol 1966; 91: 123-39. 